OPEN ACCESS

Edited by:

Divya Vohora,

Jamia Hamdard University, India

Reviewed by:

Enrique Portillo-Salido,

Welab Barcelona, Spain

Vinod Tiwari,

Indian Institute of Technology (BHU),

India

*Correspondence:

Bronwyn M. Kivell

bronwyn.kivell@vuw.ac.nz

Specialty section: This article was submitted to

Neuropharmacology,

a section of the journal

Frontiers in Pharmacology

Received: 11 November 2021

Accepted: 25 January 2022

Published: 18 February 2022

Citation:

Paton KF, Luo D, La Flamme AC, Prisinzano TE and Kivell BM (2022) Sex Differences in Kappa Opioid Receptor

Agonist Mediated Attenuation of Chemotherapy-Induced Neuropathic

Pain in Mice.

Front. Pharmacol. 13:813562.

doi: 10.3389/fphar.2022.813562

\section{Sex Differences in Kappa Opioid Receptor Agonist Mediated Attenuation of Chemotherapy- Induced Neuropathic Pain in Mice}

\author{
Kelly F. Paton ${ }^{1}$, Dan Luo ${ }^{2}$, Anne C. La Flamme ${ }^{1,3}$, Thomas E. Prisinzano ${ }^{2}$ and \\ Bronwyn M. Kivell ${ }^{1 *}$
}

${ }^{1}$ School of Biological Sciences, Centre for Biodiscovery, Victoria University of Wellington, Wellington, New Zealand, ${ }^{2}$ Department of Pharmaceutical Sciences, University of Kentucky, Lexington, KY, United States, ${ }^{3}$ Malaghan Institute of Medical Research, Wellington, New Zealand

Chemotherapy-induced neuropathic pain is a common side effect for cancer patients which has limited effective treatment options. Kappa opioid receptor (KOR) agonists are a promising alternative to currently available opioid drugs due to their low abuse potential. In the current study, we have investigated the effects of Salvinorin A (SalA) analogues, 16-Ethynyl SalA, 16-Bromo SalA and ethyoxymethyl ether (EOM) SalB, and in a preclinical model of paclitaxel-induced neuropathic pain in male and female C57BL/6J mice. Using an acute dose-response procedure, we showed that compared to morphine, 16-Ethynyl SalA was more potent at reducing mechanical allodynia; and SalA, 16-Ethynyl SalA, and EOM SalB were more potent at reducing cold allodynia. In the mechanical allodynia testing, U50,488 was more potent in males and SalA was more potent in females. There were no sex differences in the acute cold allodynia testing. In the chronic administration model, treatment with $U 50,488(10 \mathrm{mg} / \mathrm{kg})$ reduced the mechanical and cold allodynia responses to healthy levels over 23 days of treatment. Overall, we have shown that KOR agonists are effective in a model of chemotherapy-induced neuropathic pain, indicating that KOR agonists could be further developed to treat this debilitating condition.

Keywords: paclitaxel, kappa opioid receptor, salvinorin A, chemotherapy-induced neuropathic pain, sex differences

\section{INTRODUCTION}

Chemotherapy-induced peripheral neuropathy (CIPN) is a common side effect of treating cancer (Sisignano et al., 2014; Addington and Freimer, 2016) with 68\% of chemotherapy patients reporting CIPN within the first month of treatment (Seretny et al., 2014). CIPN is often characterized by spontaneous tingling or burning pain, hypersensitivity to mechanical and cold stimuli, and numbness (Forman, 1990; Dougherty et al., 2004). CIPN can be very debilitating, significantly impacting the quality of life and independence of cancer sufferers (Beijers et al., 2014; Mols et al., 2014). Often CIPN is identified as the reason for limiting either the dose or length of chemotherapy treatment and in severe CIPN cases, chemotherapy may be terminated (Holmes et al., 1991; Rowinsky et al., 1993); however, CIPN may persist for months following cessation of chemotherapy (van den Bent et al., 1997). Chemotherapy drugs that induce CIPN include vinca alkaloids, platinum derivatives and taxanes (Jaggi et al., 2011; Sisignano et al., 2014; Ewertz et al., 2015). Paclitaxel is a 
taxane chemotherapeutic widely used to treat solid tumors such as ovarian, breast, cervical, prostate, non-small cell lung, gastric, head and neck, Kaposi's sarcoma, and pancreatic cancers (Khanna et al., 2015).

The pathogenesis of paclitaxel-induced neuropathic pain involves dying-back axonal damage. This causes distal sensory axons to degenerate in the peripheral nervous system, and causes sensitization of nociceptive afferents leading to neuropathic pain symptoms in the hands and feet in a "stocking and glove"-type distribution (Forman, 1990; Dougherty et al., 2004). The American Society of Clinical Oncology clinical practice guideline states there are no recommended therapeutics for the prevention of CIPN as there is not sufficient or consistent evidence from any randomized placebo-controlled trials (Hershman et al., 2014; Loprinzi et al., 2020). For the treatment of established CIPN, the serotonin-norepinephrine reuptake inhibitor duloxetine is the only agent which is moderately recommended (Hershman et al., 2014; Loprinzi et al., 2020). Mu opioid receptor (MOR) analgesics, including hydrocodone, morphine, oxycodone, methadone, and fentanyl patches or tramadol are considered a third-line therapy (Finnerup et al., 2015; Grace et al., 2016); however, MOR agonists are still commonly used to treat CIPN, with a recent study finding that $97 \%$ of CIPN patients used opioid therapy (Shah et al., 2018).

MOR agonists are associated with many side effects and can induce hyperalgesia (Grace et al., 2016), respiratory depression (Pattinson, 2008; Dahan et al., 2010), tolerance (Chu et al., 2006; Uniyal et al., 2020), and addiction (Compton and Volkow, 2006). In comparison, kappa opioid receptor (KOR) agonists do not have rewarding effects (Vonvoigtlander et al., 1983), and are not associated with respiratory depression (Freye et al., 1983) or gastrointestinal transit (Porreca et al., 1984), and have potential to treat pain (Beck et al., 2019; Paton et al., 2020a). The naturally occurring KOR agonist, Salvinorin A (SalA), has been used as a chemical scaffold to produce analogues with greater metabolic stability and potency. We investigated two analogues with alterations at the carbon-16 position, 16Ethynyl SalA and 16-Bromo SalA, and one analogue at the carbon-2 position, ethoxymethyl ether Salvinorin B (EOM SalB). We have previously shown that 16-Ethynyl SalA and 16-Bromo SalA have antinociceptive effects in preclinical models of pain in mice, have a longer duration of action than SalA, and have improved side effect profiles (Paton et al., 2020b). Therefore, in the current study we have assessed the effect of 16-Ethynyl SalA, 16-Bromo SalA and EOM SalB in mice with paclitaxel-induced neuropathic pain. Furthermore, the majority of preclinical studies of the paclitaxel-induced neuropathic pain model have used male animals (Naji-Esfahani et al., 2016); however, in chronic pain studies, women typically have increased pain sensitivity and higher prevalence of clinical pain (Mogil, 2012; Bartley and Fillingim, 2013), and respond differently to pain medications (Pieretti et al., 2016). Therefore, we sought to understand the sex differences in the progression of paclitaxelinduced neuropathic pain and the differences in KOR treatment outcomes.

\section{MATERIALS AND METHODS}

\section{Animals}

Female and male C57BL/6J mice ( $8+$ weeks old) were used for all experiments. Animals were bred and housed at the Victoria University of Wellington (VUW) Animal Facility, Wellington, New Zealand. Animals were originally sourced from the Jackson Laboratories (Bar Harbour, ME, United States). All animals were group-housed (maximum $5 \mathrm{mice} / \mathrm{cage}$ ) in a temperature $\left(20-22^{\circ} \mathrm{C}\right)$ and humidity (55\%) controlled environment. The animals were maintained on a 12-h light/ dark cycle with lights on at 7 a.m. Access to food and water was provided ad libitum except during experimental sessions. For all paclitaxel-induced neuropathic pain experiments, soft paper/ pulp-based Carefresh Natural bedding (Masterpet, Lower Hutt, NZ) was used in the home cage to avoid any mechanical stimulation to the paw. Each cage had shredded nesting material as environmental enrichment.

All experimental procedures were undertaken during the light cycle and in presence of white noise. Animals were handled for at least 2 days before testing to acclimatise to handling and prevent stress during experimental procedures. Animals were habituated to the experimental room for $30 \mathrm{~min}$ each day. All procedures were carried out with the approval of the VUW Animal Ethics Committee (approval numbers 21480 and 25751). All procedures were carried out in agreement with the New Zealand Animal Welfare Act, 1999.

\section{Drug Preparation}

SalA was isolated and purified from Salvia divinorum leaves and assessed for purity (>98\%) using high-performance liquid chromatography (HPLC) (Munro and Rizzacasa, 2003; Tidgewell et al., 2004). The SalA analogues were synthesized as previously described (Prevatt-Smith et al., 2011; Riley et al., 2014) and tested for purity (>95\%) with HPLC. The prototypical KOR agonist U50,488 was purchased from Sigma-Aldrich (St. Louis, MO, United States) and morphine sulphate from Hospira NZ Ltd (Wellington, New Zealand). The compounds were dissolved in a vehicle containing DMSO, Tween-80 (SigmaAldrich), and $0.9 \%$ saline at a ratio of $2: 1: 7$, respectively. The compounds were delivered at a volume of $10 \mu \mathrm{l} / \mathrm{g}$ of weight via intraperitoneal (i.p.) injection and delivered at $5 \mu \mathrm{l} / \mathrm{g}$ via subcutaneous (s.c.) injection in the dose-response experiments. The KOR antagonist nor-BNI (Sigma-Aldrich) was dissolved in $0.9 \%$ saline and injected s.c. $24 \mathrm{~h}$ before testing to selectively antagonize the KOR, as earlier pre-treatment intervals have been shown to also antagonize the MOR (Endoh et al., 1992; Kishioka et al., 2013).

\section{Induction of Paclitaxel-Induced Neuropathic Pain}

Paclitaxel (Taxol, Tocris Bioscience \#RDS109750, Bristol, United Kingdom) was made fresh daily by dissolving in absolute ethanol, cremophor EL (Sigma-Aldrich) and $0.9 \%$ saline at a ratio of 1:1:18, respectively. Experimental procedures were as previously described (Deng et al., 2015; 
Paton et al., 2017; Atigari et al., 2020). Mice were administered paclitaxel $4 \mathrm{mg} / \mathrm{kg}$ i.p. injections on four alternate days to give a cumulative dose of $16 \mathrm{mg} / \mathrm{kg}$. Mechanical and cold allodynia were assessed every second day to measure the progression of paclitaxel-induced effects. Mice were placed in transparent plastic chambers upon a metal mesh stand. After a $20 \mathrm{~min}$ habituation to the apparatus, each hind paw was measured in duplicate for each type of stimulation, always beginning with mechanical testing. On days with behavioural measurements and a paclitaxel dose, measurements were always taken before the administration of paclitaxel.

\section{Von Frey Filament Procedure}

Mechanical allodynia was measured using a 20-piece set of Semmes Weinstein von Frey filaments (\#58011, Stoelting, IL, United States) as previously described (Paton et al., 2017; Atigari et al., 2020). Filaments numbered from 2 to 9 were used, with testing always beginning with filament number 5 . The filament was applied at a right angle to the plantar surface of the hind paw with enough force to produce a slight bend. The filaments were held for $3 \mathrm{~s}$ or until a positive withdrawal response was observed. Mechanical allodynia was measured using a simplified up-down method until 5 filaments had been administered (Bonin et al., 2014). Mechanical allodynia for each animal was calculated by averaging the paw withdrawal thresholds from duplicate values for each hind paw.

\section{Acetone Test}

Using a $1 \mathrm{ml}$ syringe, a bubble of acetone was administered to the plantar surface of the hind paw with care not to cause any mechanical stimulation. The amount of time the animal reacted to the stimulus was recorded for $60 \mathrm{~s}$ following application. A positive reaction was defined as elevating, licking, biting or shaking of the paw. Two measurements were taken for each hind paw alternately, with $5 \mathrm{~min}$ between consecutive applications. Cold allodynia for each animal was calculated by averaging the duration of time spent responding to the acetone across the 4 applications.

\section{Acute Dose-Response in Paclitaxel-Treated Mice}

On day 15, the cumulative dose-response effects were assessed in the paclitaxel-treated mice using a within-animals design (Paton et al., 2017; Atigari et al., 2020). The KOR agonists, morphine, or equivalent volumes of the vehicle were administered via s. c. injection every $30 \mathrm{~min}$ at increasing concentrations to create cumulative doses, with the mechanical and cold allodynia measured $30 \mathrm{~min}$ following each dose. The effects were measured in each hind paw once for each dose.

\section{Chronic Administration of Treatment in Mice With Paclitaxel-Induced Neuropathic Pain}

The efficacy and tolerance effects of chronic administration of the KOR agonists were measured in mice with established paclitaxelinduced neuropathic pain. Following the measurements on day 15 , animals were assigned to treatment groups to ensure an equivalent average mechanical allodynia score across all groups. The experimenter was blinded to the treatments each animal received. The doses used were based on the $\mathrm{ED}_{80}$ value obtained from the mechanical allodynia dose-response results. Animals were given daily i.p. injections starting on day 16 . The treatments were as follows: 16-Ethynyl SalA, $3 \mathrm{mg} / \mathrm{kg}$; 16-Bromo SalA, $4 \mathrm{mg} / \mathrm{kg} ;$ U50,488, $10 \mathrm{mg} / \mathrm{kg}$; morphine, $10 \mathrm{mg} / \mathrm{kg}$; and vehicle. On all the even-numbered days the treatment was given $30 \mathrm{~min}$ before mechanical and cold allodynia testing.

\section{Statistical Analysis}

GraphPad Prism (version 7.03, GraphPad Software, La Jolla, CA, United States) and SPSS Statistics (version 25, IBM, Armonk, NY, United States) were used to determine statistical significance. Values represented as the mean \pm standard error of the mean (SEM) and were considered significant when $p<0.05$. The data sets were tested for normality using the D'Agostino and Pearson omnibus normality test. Comparison of multiple treatment data was analyzed using one-way analysis of variance (ANOVA) followed by Bonferroni post-tests. Comparisons of multiple effects were analyzed using two-way ANOVA followed by Bonferroni post-tests. Two-way repeated-measures ANOVA was used when one variable was measured over time.

Dose-response data were analyzed by creating a non-linear regression. A four-parameter variable slope with least-squares ordinary fit was used to fit the curve to the data sets. For mechanical allodynia, the top constraint was set no more than 9.5. For cold allodynia, the bottom constraint was set at no less than 0 . The extra sum-of-squares $F$ test with the bottom, top, $\log \mathrm{ED}_{50}$ and hillslope parameters was used to compare the treatment curves, and with the null hypothesis that one curve fits all data sets. If the results showed a different curve fit for each data set, then the $\mathrm{ED}_{50}$ and $\mathrm{E}_{\max }$ values were compared with oneway ANOVA analysis.

The effects of treatment, sex and time were analyzed with a three-way repeated-measures mixed ANOVA, with treatment and sex as between-subjects variables, and time as the withinsubjects variable. The normality of the data was assessed with the Shapiro-Wilk test using the standardized residuals. The homogeneity of variances was measured using Levene's test of equality of error variances. If the data was non-normal and had unequal variances at some time points, then the data was transformed. The sphericity of the data was tested using Mauchly's test. If the $p<0.05$, the assumption of sphericity was violated and the Greenhouse-Geisser correction was applied. The Bonferroni correction was applied for multiple families of comparisons and the adjusted a level reported.

\section{RESULTS}

This study aimed to understand the effects of KOR agonists (Figure 1) for the treatment of paclitaxel-induced neuropathic pain in male and female mice. Initially, we investigated the sex differences throughout the progression of the paclitaxel-induced neuropathic pain model. A three-way repeated-measures mixed ANOVA was run to understand the effects of treatment, sex, and 
<smiles>CC(=O)O[C@H]1C[C@@H](C(C)=O)[C@@]2(C)CC[C@H]3C(=O)O[C@H](c4ccoc4)C[C@H]3[C@H]2C1=O</smiles>

Salvinorin A (Sal A)

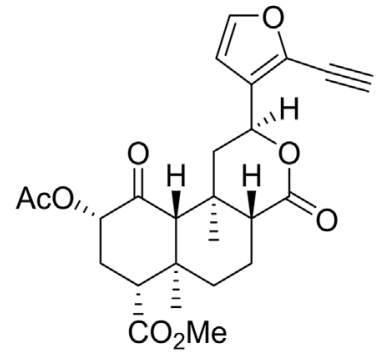

16-Ethynyl SalA<smiles>CC(=O)OC1C[C@H](C(C)=O)[C@]23CC[C@H]4C(=O)O[C@H](c5ccoc5Br)C[C@H]4[C@H]2C(=O)C13</smiles>

16-Bromo SalA<smiles>CCOCO[C@H]1C[C@@H](C(C)=O)[C@@]2(CCC3C(=O)O[C@H](c4ccoc4)C[C@H]32)CC1=O</smiles>

EOM SalB<smiles>CN(C(=O)Cc1ccc(Cl)c(Cl)c1)C1CCCC[C@H]1N1CCCC1</smiles>

U50,488

FIGURE 1 | Chemical structures of Salvinorin A, 16-Ethynyl SalA, 16-Bromo SalA, EOM SalB, and U50,488.

time on the mechanical withdrawal thresholds. The three-way interaction of treatment, sex and time was not statistically significant $\left[\mathrm{F}_{(6.183,717.2)}=2.053, p=0.055\right]$ (Figure 2A). There was a statistically significant two-way interaction between treatment and time $\left[\mathrm{F}_{(6.183,717.2)}=66.771, p<0.0005\right]$ and between treatment and $\operatorname{sex}\left[\mathrm{F}_{(1,116)}=9.744, p=0.002\right]$. Statistical significance of a simple main effect was accepted at a Bonferroni-adjusted alpha level of 0.006 due to multiple families of comparisons. There was a statistically significant simple main effect of treatment at days 4-15 $(p<0.006)$. The simple main effects of sex were not significant on any day. Overall, this shows that the paclitaxel treatment group was significantly different to the vehicle treatment group, but there were no sex differences.

A three-way repeated-measures mixed ANOVA was run to understand the effects of treatment, sex and time on the reaction times to the cold acetone stimulus. The three-way interaction was statistically significant $\left[\mathrm{F}_{(6.618,767.7)}=3.284, p=0.002\right]$ (Figure 2B). There was not a significant simple two-way interaction of treatment and sex at any time point $(p>0.006)$, however, there was a significant main effect of both treatment and sex on days $2-15(p<0.006)$. Overall, this means that there is an effect of paclitaxel treatment and an inherent difference between the sexes reaction to the cold stimulus, however, the effect of paclitaxel on each sex does not change over time.

\section{Cumulative Dose-Response Effects of Kappa Opioid Receptor Agonists}

The dose-response effects of the KOR agonists were measured to understand and compare the potency and efficacy of each drug in both sexes. All of the curves were analyzed separated for sex, showing that a different curve fits each data set for the treatment of mechanical $\left[\mathrm{F}_{(22,450)}=9.915, p<0.0001\right]$ and cold allodynia $\left[\mathrm{F}_{(22,450)}=13.33, p<0.0001\right]$ (Figures 2D-G). The potencies (ED $\mathrm{ED}_{50}$ values) were compared by treatment and sex (Table 1). For mechanical allodynia, treatment with U50,488 in males was more potent than females $(p=0.0136)$, whilst the opposite was found with SalA, and with treatment in females significantly more potent than males $(p=0.0040)$. Morphine, 16-Ethynyl SalA, 16-Bromo SalA, and EOM SalB had no significant difference between the sexes. When the male treatment groups were compared to morphine, only 16-Ethynyl SalA was significantly more potent $(p=0.0152)$. When compared to the female morphine treatment group, SalA $(p=0.0098)$ and 16-Ethynyl SalA $(p=0.0242)$ were significantly more potent.

For the treatment of cold allodynia, the two-way ANOVA found no interaction of sex and treatment $\left[\mathrm{F}_{(5,450)}=0.329, p=\right.$ 0.8955] (Table 2). Therefore, only the data with the combined sexes could be compared, showing SalA $(p=0.0034)$ and 16Ethynyl SalA $(p<0.0001)$ had significantly more potent antinociceptive effects than morphine.

\section{Antagonism of the Kappa Opioid Receptor} 16-Ethynyl SalA, 16-Bromo SalA, and U50,488 were antagonized at the KOR by pre-treating with nor-BNI (Figure 3). One-way ANOVA analysis of the values at the final dose for 16-Ethynyl SalA, 16-Bromo SalA $(10 \mathrm{mg} / \mathrm{kg})$, and U50,488 $(20 \mathrm{mg} / \mathrm{kg})$ showed a significant effect of treatment for the mechanical $\left[\mathrm{F}_{(5,51)}=118.9, p<0.0001\right]$ (Figure 3A) and cold allodynia data $\left[\mathrm{F}_{(5,51)}=73.85, p<0.0001\right]$ (Figure 3B). Bonferroni post- 
A

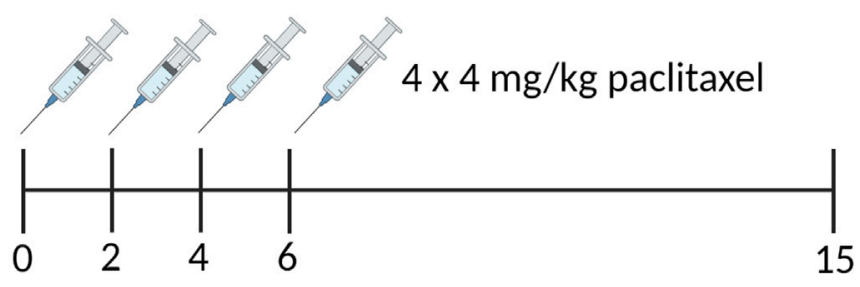

B

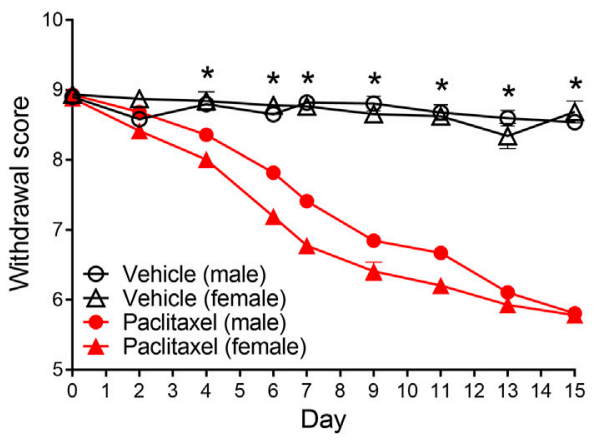

D

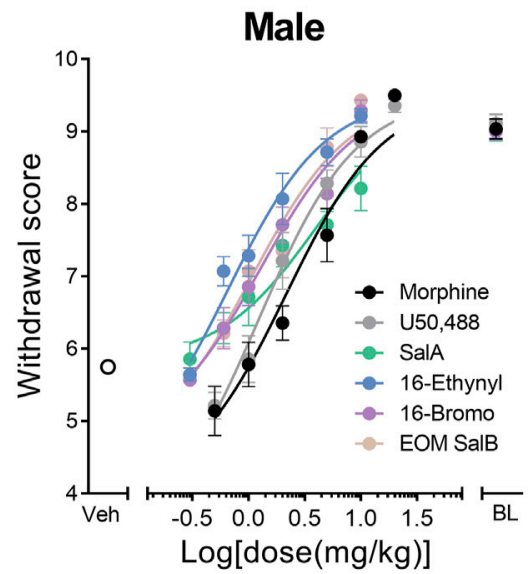

F

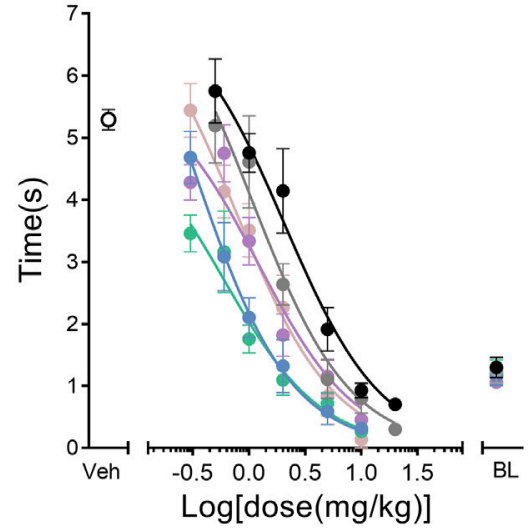

C

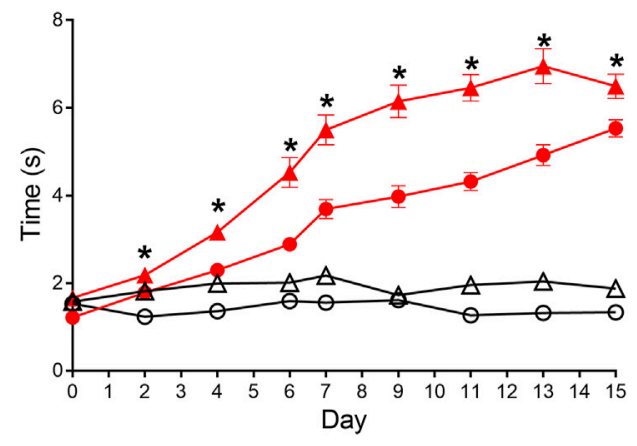

E
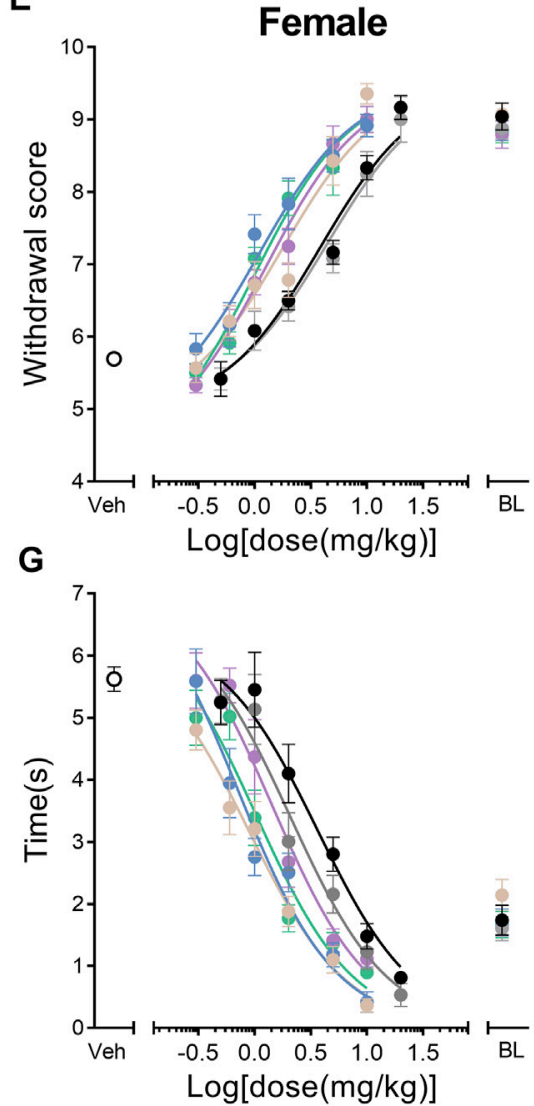

FIGURE 2 | Paclitaxel administration produces mechanical and cold allodynia in male and female C57BL/6J mice. (A) Paclitaxel was administered as 4 doses of $4 \mathrm{mg} / \mathrm{kg}$ and allodynia measured until day 15. Numbers underneath the timeline represent experimental days. (B) Paclitaxel administration produced mechanical allodynia on days 4-15, shown as a reduction in withdrawal score measured using von Frey filaments. There were no sex differences in the withdrawal scores. (C) Paclitaxel administration had a significant effect on days 2-15, with an increase in reaction time to a cold acetone stimulus. There was an effect of treatment and sex, and but no interaction of both factors, with females showing an increased reaction time in the vehicle and paclitaxel treatment groups compared to males. Three-way repeated measures mixed ANOVA. * $p<0.006$. Vehicle-treated $n=16-18$; paclitaxel-treated males $n=50$, females $n=36$. (D-G) Dose-response effects of morphine and the KOR agonists comparing male and female mice with established paclitaxel-induced neuropathic pain. Mechanical allodynia was measured in (D) males and (E) females. Cold allodynia was measured in (F) males and (G) females. Veh refers to paclitaxel-treated animals treated with vehicle. BL refers to pre-paclitaxel baseline values. $n=6-8$. Values presented as mean \pm SEM. Image in panel (A) created using BioRender.com. 
TABLE 1 | Dose-response effects of the KOR agonists in female and male mice with established paclitaxel-induced mechanical allodynia. The potency (ED 50 ) of the opioid receptor agonists were measured in mice of both sexes. U50,488 had more potent effects in males compared to females, whereas SalA was more potent in females. When the KOR treatments for each sex were compared to morphine, 16-Ethynyl SalA was significantly more potent in males and females. SalA was more potent than morphine in females only. Non-linear regression analysis. Two-way ANOVA with Bonferroni post-tests. $n=6-7$. n.s. $=$ not significant, ${ }^{*} p<0.05$, ${ }^{\star *} p<0.01$.

\begin{tabular}{|c|c|c|c|c|c|c|c|c|c|c|}
\hline \multirow{2}{*}{$\begin{array}{l}\text { Opioid receptor } \\
\text { agonist }\end{array}$} & \multicolumn{2}{|c|}{$E D_{50}$ value $(\mathrm{mg} / \mathbf{k g})$} & \multicolumn{2}{|c|}{$\log E D_{50} \pm S E M$} & \multicolumn{6}{|c|}{ Two-way ANOVA comparisons } \\
\hline & Male & Female & Male & Female & \multicolumn{2}{|c|}{ Male vs female } & \multicolumn{2}{|c|}{$\begin{array}{c}\text { Male vs. Male } \\
\text { treated with } \\
\text { morphine }\end{array}$} & \multicolumn{2}{|c|}{$\begin{array}{l}\text { Female vs. } \\
\text { Female treated } \\
\text { with morphine }\end{array}$} \\
\hline Morphine & 2.16 & 3.83 & $0.33 \pm 0.11$ & $0.58 \pm 0.07$ & $>0.9999$ & n.s. & - & & - & \\
\hline U50,488 & 1.23 & 4.38 & $0.09 \pm 0.11$ & $0.64 \pm 0.09$ & 0.0255 & * & $>0.9999$ & n.s. & $>0.9999$ & n.s. \\
\hline SalA & 3.94 & 0.99 & $0.60 \pm 0.12$ & $-0.003 \pm 0.101$ & 0.0078 & $\star \star$ & $>0.9999$ & n.s. & 0.0186 & * \\
\hline 16-Ethynyl SalA & 0.65 & 1.08 & $-0.19 \pm 0.12$ & $0.03 \pm 0.13$ & $>0.9999$ & n.s. & 0.0283 & * & 0.0447 & * \\
\hline 16-Bromo SalA & 1.27 & 1.25 & $0.10 \pm 0.01$ & $0.10 \pm 0.08$ & $>0.9999$ & n.s. & $>0.9999$ & n.s. & 0.1636 & n.s. \\
\hline EOM SalB & 1.07 & 1.76 & $0.031 \pm 0.11$ & $0.25 \pm 0.11$ & $>0.9999$ & n.s. & $>0.9999$ & n.s. & $>0.9999$ & n.s. \\
\hline
\end{tabular}

TABLE 2 |Dose-response effects of the KOR agonists in female and male mice with established paclitaxel-induced cold allodynia. Non-linear regression analysis was used to calculate the potency $\left(\mathrm{ID}_{50}\right)$ of the opioid receptor agonists in male and female mice. Two-way ANOVA showed there was no significant interaction of treatment and sex. Using the combined sex data, SalA and 16-Ethynyl SalA had more potent antinociceptive effects than morphine. The efficacy of the treatments were not significantly different. One-way ANOVA with Bonferroni post-tests. $n=6-7$. n.s. $=$ not significant, ${ }^{\star \star} p<0.01,{ }^{\star \star \star *} p<0.0001$.

\begin{tabular}{|c|c|c|c|c|c|c|c|c|}
\hline \multirow[t]{2}{*}{ Opioid receptor agonist } & \multicolumn{2}{|c|}{$\begin{array}{c}I_{50} \text { value } \\
(\mathrm{mg} / \mathrm{kg})\end{array}$} & \multicolumn{2}{|c|}{$\log I_{50} \pm S E M$} & \multirow{2}{*}{$\frac{\text { ID }_{50} \text { value }(\mathrm{mg} / \mathrm{kg})}{\text { Sexes combined }}$} & \multirow{2}{*}{$\frac{\log \mathrm{ID}_{50} \pm \mathrm{SEM}}{\text { Sexes combined }}$} & \multirow{2}{*}{\multicolumn{2}{|c|}{$\begin{array}{c}p \text { value for } \text { ID }_{50} \\
\text { compared to morphine } \\
\text { Sexes combined }\end{array}$}} \\
\hline & Male & Female & Male & Female & & & & \\
\hline Morphine & 2.06 & 3.64 & $0.31 \pm 0.12$ & $0.56 \pm 0.10$ & 2.71 & $0.43 \pm 0.08$ & - & \\
\hline U50,488 & 1.06 & 2.08 & $0.03 \pm 0.17$ & $0.32 \pm 0.12$ & 1.46 & $0.17 \pm 0.10$ & 0.3349 & n.s. \\
\hline SalA & 0.60 & 1.03 & $-0.22 \pm 0.19$ & $0.01 \pm 0.12$ & 0.82 & $-0.09 \pm 0.13$ & 0.0011 & $\star \star *$ \\
\hline 16-Ethynyl SalA & 0.31 & 0.71 & $-0.51 \pm 0.20$ & $-0.15 \pm 0.14$ & 0.48 & $-0.32 \pm 0.12$ & $<0.0001$ & $\star \star \star \star *$ \\
\hline 16-Bromo SalA & 1.20 & 1.44 & $0.08 \pm 0.13$ & $0.16 \pm 0.11$ & 1.31 & $0.12 \pm 0.09$ & 0.1607 & n.s. \\
\hline EOM SalB & 0.77 & 0.90 & $-0.11 \pm 0.14$ & $-0.04 \pm 0.12$ & 0.83 & $-0.08 \pm 0.09$ & 0.0021 & $\star \star$ \\
\hline
\end{tabular}
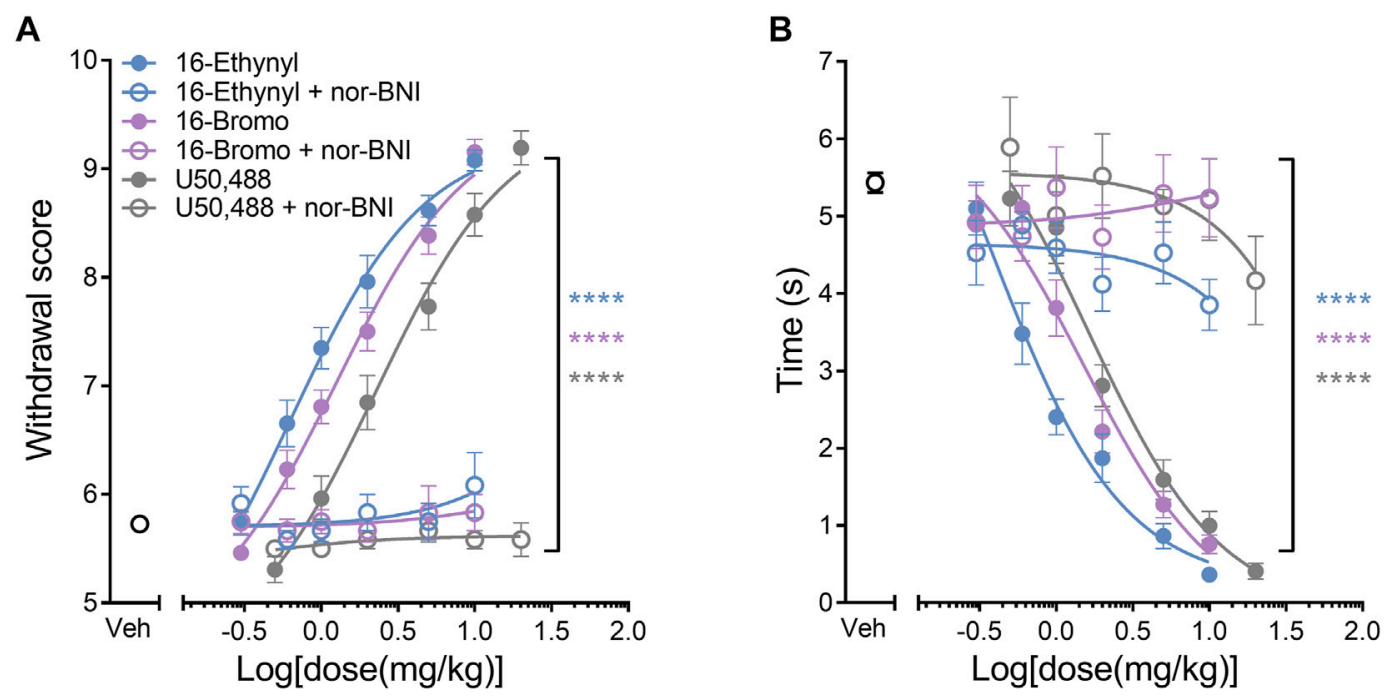

FIGURE 3 | KOR antagonism reduces the antinociceptive effect of the KOR agonists. The selective KOR antagonist nor-binaltorphimine (nor-BNI, 10 mg/kg) was administered prior to the dose-response procedure. (A) Antinociceptive dose-response effects against mechanical allodynia. Nor-BNI reduced the antinociceptive effects of the KOR agonists at the highest dose for 16-Ethynyl SalA, 16-Bromo SalA (10 mg/kg) and U50,488 (20 mg/kg) to the mechanical stimulus. (B) Antinociceptive dose-response effects against cold allodynia. Nor-BNI reduced the antinociceptive effects of the KOR agonists to the cold stimulus. One-way ANOVA with Bonferroni post-tests. Values presented as mean \pm SEM. $n=13$ for KOR agonist treatment, $n=6$ for groups with nor-BNI pre-treatment. ${ }^{\star \star \star \star} p<0.0001$ indicates comparison between treatment with and without pre-treatment of nor-BNI. 

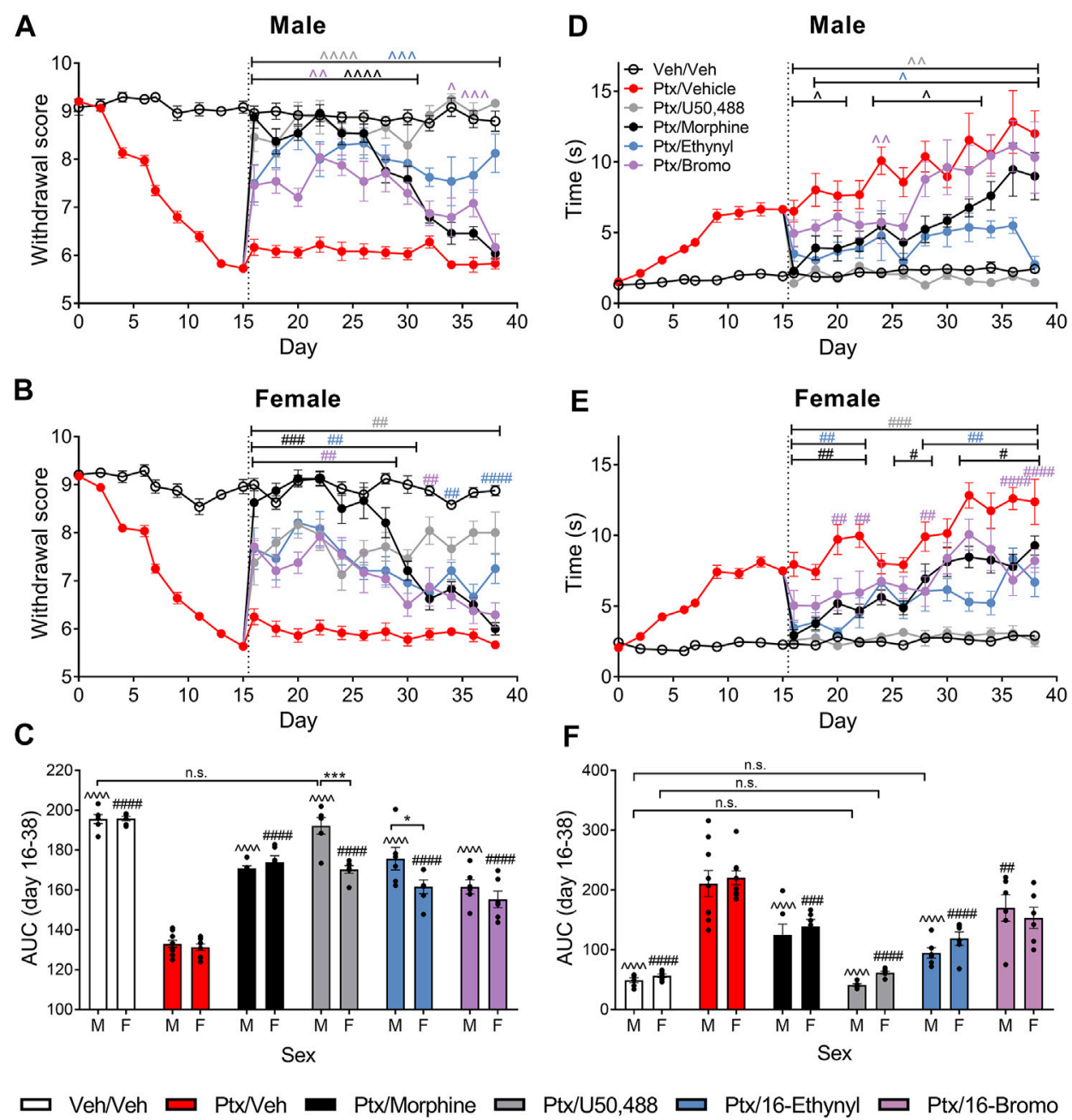

FIGURE 4 | Chronic KOR treatment reduced mechanical and cold allodynia in mice with established paclitaxel (Ptx)-induced neuropathic pain. (A, B) Time course of the treatment effects of vehicle (Veh), morphine (10 mg/kg), U50,488 (10 mg/kg), 16-Ethynyl SalA (3 mg/kg), and 16-Bromo SalA (4 mg/kg) on mechanical allodynia in (A) males and (B) females. (C) Area under the curve (AUC) comparison within the male and female animals showed treatments all significantly increased the paclitaxelinduced withdrawal scores, with U50,488 treatment in males improving the mechanical thresholds to vehicle/vehicle levels. Comparison of the sex differences in the treatments found that U50,488 and 16-Ethynyl were more effective in males. (D, E) Time course of the treatment effects on cold allodynia in (D) males and (E) females. (F) AUC analysis showed that U50,488 treatment in both sexes and 16-Ethynyl treatment in males reduced the cold stimulus responding time to the same level as vehicle/ vehicle controls. Two-way ANOVA with Bonferroni post-tests. n. s. = not significant, $p<0.05,{ }^{\wedge} p<0.01,{ }^{\wedge} p<0.005$, ^^p $p<0,001$ for male treatment group compared to

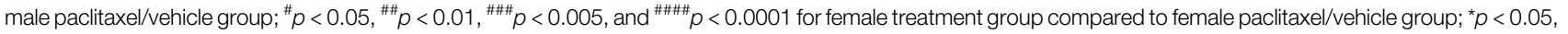
${ }^{\star \star \star} p<0.005$ for sex difference within treatment group. Values presented as mean $\pm \mathrm{SEM}, n=6-9$.

tests showed that there was a significant difference with pretreatment of nor-BNI for all KOR agonists $(p<0.0001)$. The results show that the antinociceptive actions of the novel SalA analogues are mediated via the KOR.

\section{Effect of Chronic Administration of Kappa Opioid Receptor Agonists on Mechanical Allodynia}

We further assessed the effect of the KOR agonists using a chronic administration model, in which treatment began on day 16 postinitiation of paclitaxel-induced neuropathic pain. In male mice, 16-Ethynyl SalA and U50,488 reduced paclitaxel-induced mechanical allodynia on all days evaluated $(p<0.005$; Figure 4A). Morphine treatment had antinociceptive effects on days $16-30$, and 16 -Bromo SalA on days $16-30$ and $34-36$ $(p<0.05$; Figure 4A). In the female mice, U50,488 reduced mechanical allodynia at all time points evaluated, whereas, 16Ethynyl SalA reduced mechanical allodynia at days 16-30, 34, and 38; 16-Bromo SalA at days 16-28, and 32; and morphine at days 16-30 (Figure 4C). The area under the curve (AUC) analysis showed that all treatment groups were significantly different to the paclitaxel/vehicle group within each sex $(p<0.001$; Figure 4B). Furthermore, in the males, U50,488 treatment reduced the mechanical withdrawal thresholds to healthy control levels (vehicle/vehicle treatment group; $p>0.9999$; 
Figure 4B). Further investigation into sex differences within each treatment showed that U50,488 and 16-Ethynyl SalA were more effective in male mice than female mice $(p<0.05)$, whereas, all other treatments had no sex differences (Figure 4C).

\section{Effect of Chronic Administration of Kappa Opioid Receptor Agonists on Cold Allodynia}

In male mice, U50,488 reduced the paclitaxel-induced cold allodynia at all the days evaluated (days 16-38; $p<0.01$ ); 16Ethynyl SalA attenuated cold allodynia at days $18-38$; 16-Bromo SalA at day 24; and morphine at days 16-20, 24-28, and day 32 (Figure 4D). In the female mice, U50,488 reduced the reaction time at all time points (days 16-38; $p<0.005$ ); 16-Ethynyl SalA reduced cold allodynia at days 16-22 and 28-38 ( $p<0.01)$; $16-$ Bromo SalA at days 20-22, 28 and 36-38 $(p<0.01)$; and morphine at days 16-22, 26-28, and 32-38 $(p<0.05$; Figure 4E). In male mice, AUC analysis showed all KOR agonist treatments attenuated thermal nociception; in female mice, all treatment groups except 16-Bromo SalA attenuated thermal nociception when compared to the paclitaxel/vehicle control group (Figure 4F). U50,488 (both sexes) and 16Ethynyl SalA (males only) returned antinociceptive responses to healthy control levels (vehicle/vehicle group). When the sexes were compared within each treatment, there were no significant sex differences (Figure 4F).

\section{DISCUSSION}

There is an urgent need to develop new treatments for CIPN, as this debilitating condition currently has very limited treatment options (Loprinzi et al., 2020). MOR agonists are often used to alleviate pain; however, these can potentiate pain when used chronically, and have addictive and aversive side effects (Chu et al., 2006; Compton and Volkow, 2006; Pattinson, 2008; Dahan et al., 2010; Roeckel et al., 2016). We have investigated the effect of KOR agonists for the treatment of paclitaxel-induced neuropathic pain due to the reduced abuse potential of KOR agonists, which is an important requirement for these treatments due to the longterm nature of chemotherapy regimens. We have further investigated the sex differences within our experiments due to the over-reliance on male animals used in research, which may not give an accurate representation of both sexes (Clayton and Collins, 2014; Lee, 2018; Shansky and Murphy, 2021).

We initially investigated the effect of sex on the onset of disease in the paclitaxel-induced neuropathic pain model. We showed that paclitaxel administration induces significant mechanical allodynia, with no sex differences at any time points. In contrast, measurements of cold allodynia showed the female mice had a longer reaction time in both the vehicle and paclitaxel groups. This is consistent with a previous study using NMRI mice, which found the paclitaxel-treated female mice had increased paw licking following cold stimulus to the paw between days 7-11, however, measurements on days 13 and 15 were not significantly different to males (Naji-Esfahani et al., 2016). The same study found no sex differences in the development of paclitaxel-induced mechanical allodynia measured using von Frey filaments (Naji-Esfahani et al., 2016). In further studies, there were no differences between the sexes in paclitaxel-induced mechanical allodynia in C57BL/6 mice (Smith et al., 2004); whereas in rats, there were both findings with no sex difference (Hwang et al., 2012) and with females showing greater mechanical hyperalgesia (Wang et al., 2018; Ferrari et al., 2020). Overall, the majority of studies have no inherent sex differences in paclitaxel-induced mechanical allodynia, whereas multiple studies have shown females to have a heightened cold response.

The antinociceptive dose-response effects of the KOR agonists were evaluated alongside morphine to assess the potency of the compounds in both sexes. The mechanical testing showed U50,488 was significantly more potent in males compared to females. It has been shown in previous studies that U50,488 exhibits higher antinociceptive potency in males when measured with the tail withdrawal assay (reviewed in Rasakham and LiuChen, 2011). However, in a similar paclitaxel-induced experiment performed in Sprague Dawley rats, acute morphine treatment (2-5 mg/kg i.p.) had the same antinociceptive effects in both sexes with mechanical allodynia (Hwang et al., 2012). We also found that SalA treatment was more potent in females. Interestingly, in rhesus macaques, SalA has sex differences in the pharmacokinetic effects, with females showing a slower elimination from plasma and a larger area under the concentration-time curve following intravenous injection (Schmidt et al., 2005), which may explain the increased antinociceptive effects produced in females. We also showed that 16-Ethynyl SalA was more potent than morphine for treatment of both mechanical and cold allodynia, which is similar to our previous study showing 16-Ethynyl SalA was more potent and efficacious than U50,488 in the warm water tail withdrawal assay (Paton et al., 2020b).

There are few previous studies measuring the effects of KOR agonists in a model of paclitaxel-induced neuropathic pain. We have shown the SalA analogue, $\beta$-tetrahydropyran SalB, and the mixed opioid receptor agonist MP1104 have anti-allodynic effects in this model (Paton et al., 2017; Atigari et al., 2020). In an alternative CIPN model, KOR agonist LOR17 was found to alleviate oxaliplatin-induced thermal hypersensitivity to a cold stimulus, and was more potent than U50,488 (Bedini et al., 2020). SalA has also been assessed in other models of neuropathic pain. SalA reduced pain in a sciatic nerve ligature model in male Wistar rats when injected directly into the insular cortex (Coffeen et al., 2018). Furthermore, an extract of Salvia divinorum, containing SalA, SalB, and other substances found in the leaves of the plant, reduced mechanical and thermal sciatic nerve ligature neuropathic pain when administered at $100-200 \mathrm{mg} / \mathrm{kg}$ i.p. (Simon-Arceo et al., 2017). The effect of KOR agonists in CIPN is an emerging area of research, however, these studies set the groundwork to show that KOR agonists have promise at treating neuropathic pain.

Several studies have assessed the effects of MOR agonists in the paclitaxel-induced neuropathic pain model. In male C57BL/6J mice, previous findings show morphine with an $\mathrm{ED}_{50}$ of $6.68 \mathrm{mg} / \mathrm{kg}$ against mechanical allodynia and $12.5 \mathrm{mg} / \mathrm{kg}$ against cold allodynia (Slivicki et al., 2018), whereas, we found that morphine was 3-6 fold more potent (mechanical allodynia 
$\mathrm{ED}_{50}$ of $2.16 \mathrm{mg} / \mathrm{kg}$; cold allodynia $\mathrm{ED}_{50}$ of $2.06 \mathrm{mg} / \mathrm{kg}$ ). The effects in both studies were done at $30 \mathrm{~min}$ post-injection, however, the dose-response in the Slivicki et al. (2018) study was done over multiple days rather than a cumulative doseresponse in one session. Previous work has indicated that discrete versus cumulative dose-response procedures yield the same results (Schechter, 1997). A further difference between the studies is Slivicki et al. (2018) used an electronic von Frey anesthesiometer, whereas the current study used classical von Frey filaments of varying diameter. The electronic von Frey anesthesiometer may give more continuous data, as opposed to the individual von Frey filaments that each exert a discrete maximum force, and the electronic von Frey apparatus is believed to be more sensitive (Cunha et al., 2004).

In the current study, daily $10 \mathrm{mg} / \mathrm{kg}$ morphine administration was effective for 15 days against mechanical allodynia, whereas a previous study found morphine was only effective on the first treatment day and was no longer effective 3 days later (Slivicki et al., 2020). In male Sprague Dawley rats, Flatters and Bennett (2004) found an acute treatment of $4 \mathrm{mg} / \mathrm{kg}$ morphine was ineffective at treating paclitaxel-induced mechanical allodynia and $8 \mathrm{mg} / \mathrm{kg}$ only produced a $50 \%$ reversal of mechanical allodynia. A further study in male Sprague Dawley rats found that $4 \mathrm{mg} / \mathrm{kg}$ normalized the mechanical withdrawal thresholds to pre-paclitaxel baseline levels (Rahn et al., 2008). This shows there is great variation in the effects of morphine in the paclitaxelinduced neuropathic pain model. Reasons for variations in the results could include the use of different species (mice vs rats), different concentration of paclitaxel, the use of electronic vs. classical von Frey apparatus, and different experimental time points.

In the chronic administration regimen, we showed that U50,488 significantly reversed the effects of paclitaxel over 23 days, with no apparent tolerance effects. In the warm water $\left(55^{\circ}\right)$ tail withdrawal assay in C57BL/6 mice, U50,488 has been shown to cause tolerance effects, however, this was with an escalating dose scheme up to $75 \mathrm{mg} / \mathrm{kg}$ i.p. over 4 days (McLaughlin et al., 2004), whereas in the current study we used $10 \mathrm{mg} / \mathrm{kg}$ i.p. treatment daily. Interestingly, using a partial spinal nerve ligation model, phosphorylated KOR immunoreactivity was increased in the L4-5 dorsal horn regions of the spinal cord in male $\mathrm{C} 57 \mathrm{BL} / 6$ mice and $\mathrm{KOR}$ knock-out mice there was increased mechanical allodynia and thermal heat hyperalgesia (Xu et al., 2004). However, due to this endogenous KOR activation in the mice with neuropathic pain, treatment with $\mathrm{U} 50,488$ showed increased tolerance compared to sham, and this tolerance effect was absent in prodynorphin or GRK3 knock-out mice (Xu et al., 2004). Furthermore, KOR antagonism with nor-BNI in mice and rats led to increased levels of mechanical and thermal allodynia (Obara et al., 2003). In comparing to the current study, because U50,488 does not show the tolerance effects associated with endogenous KOR activation, it could be that the endogenous KOR system is not activated to the same extent in the paclitaxel-induced neuropathic pain model compared to the partial spinal nerve ligation model; however, this effect has not been studied.
Interestingly, the KOR mediates the initial aversive component of paclitaxel-induced neuropathic pain (day 8), with an increase in prodynorphin levels in the nucleus accumbens (Meade et al., 2020). Due to this aversive nature of the pain, it is important to develop treatments that do not have negative side effects. We have previously shown that 16 -Bromo SalA does not have anxiogenic effect in the elevated zero maze and the marble burying test; however, 16-Ethynyl SalA did significantly reduce exploratory behaviors in the elevated zero maze but had no effect in the marble burying test (Paton et al., 2020b). Furthermore, the sedative effects of the treatments should be considered, we know that 16-Ethynyl SalA, 16-Bromo SalA, and $\mathrm{U} 50,488$ have motor incoordination effects in the rotarod performance test (Paton et al., 2020b; Dunn et al., 2020); however, 16-Bromo SalA and 16-Ethynyl SalA did not reduce spontaneous locomotor activity at lower doses in rats (Riley et al., 2014). Even though the duration of action of these novel SalA analogues is longer than the parent compound (Paton et al., 2020b), the relatively short duration of action and negative side effects may hinder progression of these compounds into a clinical setting. However, these compounds show proof-of-concept that KOR agonists can be used for this form of neuropathic pain. In addition, there has been some progress in developing peripherally-restricted MOR agonists for the treatment of neuropathic pain (Tiwari et al., 2018), so further investigation into the mechanism of action could indicate whether a peripherally-restricted KOR agonist could be developed with no centrally-active side effects.

In conclusion, we have shown that KOR agonists have antiallodynic effects in a mouse model of CIPN and are more potent than morphine for the treatment of paclitaxel-induced neuropathic pain. We have shown that U50,488 was more potent in male mice; whereas, SalA treatment was more potent in females. In the chronic administration paradigm, treatment with U50,488 reversed the paclitaxel-induced allodynia to healthy levels. Therefore, this study provides evidence that KOR agonists have potential for treating pain conditions associated with chronic neuropathy such as CIPN by reducing allodynia.

\section{DATA AVAILABILITY STATEMENT}

The raw data supporting the conclusion of this article will be made available by the authors, without undue reservation.

\section{ETHICS STATEMENT}

The animal study was reviewed and approved by the Victoria University of Wellington Animal Ethics Committee.

\section{AUTHOR CONTRIBUTIONS}

$\mathrm{KP}, \mathrm{AL}, \mathrm{TP}$, and BK contributed to the design of the study. DL and TP provided the kappa opioid receptor agonists. KP conducted the experiments and performed the data analysis. 
KP wrote the first draft of the manuscript. DL, AL, TP, and BK critically evaluated the manuscript. All authors contributed to the manuscript revision, read and approved the submitted version.

\section{FUNDING}

This work was supported by the Health Research Council of New Zealand (Explorer grant number 16/646 to BK), Cancer Society of New Zealand Wellington Division (to BK) and the

\section{REFERENCES}

Addington, J., and Freimer, M. (2016). Chemotherapy-induced Peripheral Neuropathy: an Update on the Current Understanding. F1000Res 5, F1000 Faculty Rev-1466. doi:10.12688/f1000research.8053.1

Atigari, D. V., Paton, K. F., Uprety, R., Váradi, A., Alder, A. F., Scouller, B., et al. (2021). The Mixed Kappa and delta Opioid Receptor Agonist, MP1104, Attenuates Chemotherapy-Induced Neuropathic Pain. Neuropharmacology 185, 108445. doi:10.1016/j.neuropharm.2020.108445

Bartley, E. J., and Fillingim, R. B. (2013). Sex Differences in Pain: a Brief Review of Clinical and Experimental Findings. Br. J. Anaesth. 111 (1), 52-58. doi:10.1093/ bja/aet127

Beck, T. C., Hapstack, M. A., Beck, K. R., and Dix, T. A. (2019). Therapeutic Potential of Kappa Opioid Agonists. Pharmaceuticals (Basel) 12 (2), 95. doi:10. 3390/ph12020095

Bedini, A., Di Cesare Mannelli, L., Micheli, L., Baiula, M., Vaca, G., De Marco, R., et al. (2020). Functional Selectivity and Antinociceptive Effects of a Novel KOPr Agonist. Front. Pharmacol. 11 (188), 188. doi:10.3389/fphar. 2020.00188

Beijers, A., Mols, F., Dercksen, W., Driessen, C., and Vreugdenhil, G. (2014). Chemotherapy-induced Peripheral Neuropathy and Impact on Quality of Life 6 Months after Treatment with Chemotherapy. J. Community Support. Oncol. 12 (11), 401-406. doi:10.12788/jcso.0086

Bonin, R. P., Bories, C., and De Koninck, Y. (2014). A simplified up-down method (SUDO) for measuring mechanical nociception in rodents using von Frey filaments. Mol. Pain 10 (1), 26. doi:10.1186/1744-8069-10-26

Chu, L. F., Clark, D. J., and Angst, M. S. (2006). Opioid Tolerance and Hyperalgesia in Chronic Pain Patients after One Month of Oral Morphine Therapy: a Preliminary Prospective Study. J. Pain 7 (1), 43-48. doi:10.1016/j.jpain.2005. 08.001

Clayton, J. A., and Collins, F. S. (2014). Policy: NIH to Balance Sex in Cell and Animal Studies. Nature 509 (7500), 282-283. doi:10.1038/509282a

Coffeen, U., Canseco-Alba, A., Simón-Arceo, K., Almanza, A., Mercado, F., LeónOlea, M., et al. (2018). Salvinorin A Reduces Neuropathic Nociception in the Insular Cortex of the Rat. Eur. J. Pain 22 (2), 311-318. doi:10.1002/ejp.1120

Compton, W. M., and Volkow, N. D. (2006). Major Increases in Opioid Analgesic Abuse in the United States: Concerns and Strategies. Drug Alcohol Depend 81 (2), 103-107. doi:10.1016/j.drugalcdep.2005.05.009

Cunha, T. M., Verri, W. A., Jr., Vivancos, G. G., Moreira, I. F., Reis, S., Parada, C. A., et al. (2004). An Electronic Pressure-Meter Nociception Paw Test for Mice. Braz. J. Med. Biol. Res. 37 (3), 401-407. doi:10.1590/s0100-879x2004000300018

Dahan, A., Aarts, L., and Smith, T. W. (2010). Incidence, Reversal, and Prevention of Opioid-Induced Respiratory Depression. Anesthesiology 112 (1), 226-238. doi:10.1097/ALN.0b013e3181c38c25

Deng, L., Guindon, J., Cornett, B. L., Makriyannis, A., Mackie, K., and Hohmann, A. G. (2015). Chronic Cannabinoid Receptor 2 Activation Reverses Paclitaxel Neuropathy without Tolerance or Cannabinoid Receptor 1-dependent Withdrawal. Biol. Psychiatry 77 (5), 475-487. doi:10.1016/j.biopsych.2014. 04.009

Dougherty, P. M., Cata, J. P., Cordella, J. V., Burton, A., and Weng, H. R. (2004). Taxol-induced Sensory Disturbance Is Characterized by Preferential Impairment of Myelinated Fiber Function in Cancer Patients. Pain 109 (12), 132-142. doi:10.1016/j.pain.2004.01.021
National Institute of Drug Abuse (Grant number DA018151 to TP). KP received a doctoral scholarship from Victoria University of Wellington.

\section{ACKNOWLEDGMENTS}

The authors would like to acknowledge Shaun Graham (Victoria University of Wellington) who built the chambers and stand used to assess allodynia.

Dunn, A., Windisch, K., Ben-Ezra, A., Pikus, P., Morochnik, M., Erazo, J., et al. (2020). Modulation of Cocaine-Related Behaviors by Low Doses of the Potent KOR Agonist Nalfurafine in Male C57BL6 Mice. Psychopharmacology (Berl) 237 (8), 2405-2418. doi:10.1007/s00213-020-05543-7

Endoh, T., Matsuura, H., Tanaka, C., and Nagase, H. (1992). Nor-binaltorphimine: a Potent and Selective Kappa-Opioid Receptor Antagonist with Long-Lasting Activity In Vivo. Arch. Int. Pharmacodyn Ther. 316, 30-42.

Ewertz, M., Qvortrup, C., and Eckhoff, L. (2015). Chemotherapy-induced Peripheral Neuropathy in Patients Treated with Taxanes and Platinum Derivatives. Acta Oncol. 54 (5), 587-591. doi:10.3109/0284186X.2014.995775

Ferrari, L. F., Araldi, D., Green, P. G., and Levine, J. D. (2020). Marked Sexual Dimorphism in Neuroendocrine Mechanisms for the Exacerbation of Paclitaxel-Induced Painful Peripheral Neuropathy by Stress. Pain 161 (4), 865-874. doi:10.1097/j.pain.0000000000001798

Finnerup, N. B., Attal, N., Haroutounian, S., McNicol, E., Baron, R., Dworkin, R. H., et al. (2015). Pharmacotherapy for Neuropathic Pain in Adults: a Systematic Review and Meta-Analysis. Lancet Neurol. 14 (2), 162-173. doi:10.1016/S14744422(14)70251-0

Flatters, S. J., and Bennett, G. J. (2004). Ethosuximide Reverses Paclitaxel- and Vincristine-Induced Painful Peripheral Neuropathy. Pain 109 (1-2), 150-161. doi:10.1016/j.pain.2004.01.029

Forman, A. (1990). Peripheral Neuropathy in Cancer Patients: Clinical Types, Etiology, and Presentation. Part 2. Oncology (Williston Park) 4 (2), 85-89.

Freye, E., Hartung, E., and Schenk, G. K. (1983). Bremazocine: an Opiate that Induces Sedation and Analgesia without Respiratory Depression. Anesth. Analg 62 (5), 483-488. doi:10.1213/00000539-198305000-00005

Grace, P. M., Strand, K. A., Galer, E. L., Urban, D. J., Wang, X., Baratta, M. V., et al. (2016). Morphine Paradoxically Prolongs Neuropathic Pain in Rats by Amplifying Spinal NLRP3 Inflammasome Activation. Proc. Natl. Acad. Sci. U S A. 113 (24), E3441-E3450. doi:10.1073/pnas.1602070113

Hershman, D. L., Lacchetti, C., Dworkin, R. H., Lavoie Smith, E. M., Bleeker, J., Cavaletti, G., et al. (2014). Prevention and Management of ChemotherapyInduced Peripheral Neuropathy in Survivors of Adult Cancers: American Society of Clinical Oncology Clinical Practice Guideline. J. Clin. Oncol. 32 (18), 1941-1967. doi:10.1200/JCO.2013.54.0914

Holmes, F. A., Walters, R. S., Theriault, R. L., Forman, A. D., Newton, L. K., Raber, M. N., et al. (1991). Phase II Trial of Taxol, an Active Drug in the Treatment of Metastatic Breast Cancer. J. Natl. Cancer Inst. 83 (24), 1797-1805. doi:10.1093/ jnci/83.24.1797-a

Hwang, B. Y., Kim, E. S., Kim, C. H., Kwon, J. Y., and Kim, H. K. (2012). Gender Differences in Paclitaxel-Induced Neuropathic Pain Behavior and Analgesic Response in Rats. Korean J. Anesthesiol 62 (1), 66-72. doi:10.4097/kjae.2012.62. 1.66

Jaggi, A. S., Jain, V., and Singh, N. (2011). Animal Models of Neuropathic Pain. Fundam. Clin. Pharmacol. 25 (1), 1-28. doi:10.1111/j.1472-8206.2009.00801.x

Khanna, C., Rosenberg, M., and Vail, D. M. (2015). A Review of Paclitaxel and Novel Formulations Including Those Suitable for Use in Dogs. J. Vet. Intern. Med. 29 (4), 1006-1012. doi:10.1111/jvim.12596

Kishioka, S., Kiguchi, N., Kobayashi, Y., Yamamoto, C., Saika, F., Wakida, N., et al. (2013). Pharmacokinetic Evidence for the Long-Lasting Effect of NorBinaltorphimine, a Potent Kappa Opioid Receptor Antagonist, in Mice. Neurosci. Lett. 552, 98-102. doi:10.1016/j.neulet.2013.07.040

Lee, S. K. (2018). Sex as an Important Biological Variable in Biomedical Research. BMB Rep. 51 (4), 167-173. doi:10.5483/bmbrep.2018.51.4.034 
Loprinzi, C. L., Lacchetti, C., Bleeker, J., Cavaletti, G., Chauhan, C., Hertz, D. L., et al. (2020). Prevention and Management of Chemotherapy-Induced Peripheral Neuropathy in Survivors of Adult Cancers: ASCO Guideline Update. J. Clin. Oncol. 38 (28), 3325-3348. doi:10.1200/JCO.20.01399

McLaughlin, J. P., Myers, L. C., Zarek, P. E., Caron, M. G., Lefkowitz, R. J., Czyzyk, T. A., et al. (2004). Prolonged Kappa Opioid Receptor Phosphorylation Mediated by G-Protein Receptor Kinase Underlies Sustained Analgesic Tolerance. J. Biol. Chem. 279 (3), 1810-1818. doi:10.1074/jbc.M305796200

Meade, J. A., Alkhlaif, Y., Contreras, K. M., Obeng, S., Toma, W., Sim-Selley, L. J., et al. (2020). Kappa Opioid Receptors Mediate an Initial Aversive Component of Paclitaxel-Induced Neuropathy. Psychopharmacology (Berl) 237 (9), 2777-2793. doi:10.1007/s00213-020-05572-2

Mogil, J. S. (2012). Sex Differences in Pain and Pain Inhibition: Multiple Explanations of a Controversial Phenomenon. Nat. Rev. Neurosci. 13 (12), 859-866. doi:10.1038/nrn3360

Mols, F., Beijers, T., Vreugdenhil, G., and van de Poll-Franse, L. (2014). Chemotherapy-induced Peripheral Neuropathy and its Association with Quality of Life: a Systematic Review. Support Care Cancer 22 (8), 2261-2269. doi:10.1007/s00520-014-2255-7

Munro, T. A., and Rizzacasa, M. A. (2003). Salvinorins D-F, New Neoclerodane Diterpenoids from Salvia Divinorum, and an Improved Method for the Isolation of Salvinorin A. J. Nat. Prod. 66 (5), 703-705. doi:10.1021/np0205699

Naji-Esfahani, H., Vaseghi, G., Safaeian, L., Pilehvarian, A. A., Abed, A., and Rafieian-Kopaei, M. (2016). Gender Differences in a Mouse Model of Chemotherapy-Induced Neuropathic Pain. Lab. Anim. 50 (1), 15-20. doi:10. 1177/0023677215575863

Obara, I., Mika, J., Schafer, M. K., and Przewlocka, B. (2003). Antagonists of the Kappa-Opioid Receptor Enhance Allodynia in Rats and Mice after Sciatic Nerve Ligation. Br. J. Pharmacol. 140 (3), 538-546. doi:10.1038/sj.bjp.0705427

Paton, K. F., Atigari, D. V., Kaska, S., Prisinzano, T., and Kivell, B. M. (2020a). Strategies for Developing $\kappa$ Opioid Receptor Agonists for the Treatment of Pain with Fewer Side Effects. J. Pharmacol. Exp. Ther. 375 (2), 332-348. doi:10.1124/ jpet.120.000134

Paton, K. F., Biggerstaff, A., Kaska, S., Crowley, R. S., La Flamme, A. C., Prisinzano, T. E., et al. (2020b). Evaluation of Biased and Balanced Salvinorin A Analogs in Preclinical Models of Pain. Front. Neurosci. 14 (765), 765. doi:10.3389/fnins. 2020.00765

Paton, K. F., Kumar, N., Crowley, R. S., Harper, J. L., Prisinzano, T. E., and Kivell, B. M. (2017). The Analgesic and Anti-inflammatory Effects of Salvinorin A Analogue $\beta$-tetrahydropyran Salvinorin B in Mice. Eur. J. Pain 21 (6), 1039-1050. doi:10.1002/ejp.1002

Pattinson, K. T. (2008). Opioids and the Control of Respiration. Br. J. Anaesth. 100 (6), 747-758. doi:10.1093/bja/aen094

Pieretti, S., Di Giannuario, A., Di Giovannandrea, R., Marzoli, F., Piccaro, G., Minosi, P., et al. (2016). Gender Differences in Pain and its Relief. Ann. Ist Super Sanita 52 (2), 184-189. doi:10.4415/ANN_16_02_09

Porreca, F., Mosberg, H. I., Hurst, R., Hruby, V. J., and Burks, T. F. (1984). Roles of $\mathrm{Mu}$, delta and Kappa Opioid Receptors in Spinal and Supraspinal Mediation of Gastrointestinal Transit Effects and Hot-Plate Analgesia in the Mouse. J. Pharmacol. Exp. Ther. 230 (2), 341-348.

Prevatt-Smith, K. M., Lovell, K. M., Simpson, D. S., Day, V. W., Douglas, J. T., Bosch, P., et al. (2011). Potential Drug Abuse Therapeutics Derived from the Hallucinogenic Natural Product Salvinorin A. Medchemcomm 2 (12), 1217-1222. doi:10.1039/C1MD00192B

Rahn, E. J., Zvonok, A. M., Thakur, G. A., Khanolkar, A. D., Makriyannis, A., and Hohmann, A. G. (2008). Selective Activation of Cannabinoid CB2 Receptors Suppresses Neuropathic Nociception Induced by Treatment with the Chemotherapeutic Agent Paclitaxel in Rats. J. Pharmacol. Exp. Ther. 327 (2), 584-591. doi:10.1124/jpet.108.141994

Rasakham, K., and Liu-Chen, L. Y. (2011). Sex Differences in Kappa Opioid Pharmacology. Life Sci. 88 (1-2), 2-16. doi:10.1016/j.lfs.2010.10.007

Riley, A. P., Groer, C. E., Young, D., Ewald, A. W., Kivell, B. M., and Prisinzano, T. E. (2014). Synthesis and $\kappa$-opioid Receptor Activity of Furan-Substituted Salvinorin A Analogues. J. Med. Chem. 57 (24), 10464-10475. doi:10.1021/ jm501521d

Roeckel, L. A., Le Coz, G. M., Gavériaux-Ruff, C., and Simonin, F. (2016). Opioidinduced Hyperalgesia: Cellular and Molecular Mechanisms. Neuroscience 338, 160-182. doi:10.1016/j.neuroscience.2016.06.029
Rowinsky, E. K., Chaudhry, V., Forastiere, A. A., Sartorius, S. E., Ettinger, D. S., Grochow, L. B., et al. (1993). Phase I and Pharmacologic Study of Paclitaxel and Cisplatin with Granulocyte colony-stimulating Factor: Neuromuscular Toxicity Is Dose-Limiting. J. Clin. Oncol. 11 (10), 2010-2020. doi:10.1200/JCO.1993.11. 10.2010

Schechter, M. D. (1997). Discrete versus Cumulative Dosing in Dose-Response Discrimination Studies. Eur. J. Pharmacol. 326 (2-3), 113-118. doi:10.1016/ s0014-2999(97)85404-0

Schmidt, M. D., Schmidt, M. S., Butelman, E. R., Harding, W. W., Tidgewell, K., Murry, D. J., et al. (2005). Pharmacokinetics of the Plant-Derived KappaOpioid Hallucinogen Salvinorin A in Nonhuman Primates. Synapse 58 (3), 208-210. doi:10.1002/syn.20191

Seretny, M., Currie, G. L., Sena, E. S., Ramnarine, S., Grant, R., MacLeod, M. R., et al. (2014). Incidence, Prevalence, and Predictors of Chemotherapy-Induced Peripheral Neuropathy: A Systematic Review and Meta-Analysis. Pain 155 (12), 2461-2470. doi:10.1016/j.pain.2014.09.020

Shah, A., Hoffman, E. M., Mauermann, M. L., Loprinzi, C. L., Windebank, A. J., Klein, C. J., et al. (2018). Incidence and Disease burden of ChemotherapyInduced Peripheral Neuropathy in a Population-Based Cohort. J. Neurol. Neurosurg. Psychiatry 89 (6), 636-641. doi:10.1136/jnnp-2017-317215

Shansky, R. M., and Murphy, A. Z. (2021). Considering Sex as a Biological Variable Will Require a Global Shift in Science Culture. Nat. Neurosci. 24 (4), 457-464. doi:10.1038/s41593-021-00806-8

Simon-Arceo, K., González-Trujano, M. E., Coffeen, U., Fernández-Mas, R., Mercado, F., Almanza, A., et al. (2017). Neuropathic and Inflammatory Antinociceptive Effects and Electrocortical Changes Produced by Salvia Divinorum in Rats. J. Ethnopharmacol 206, 115-124. doi:10.1016/j.jep.2017. 05.016

Sisignano, M., Baron, R., Scholich, K., and Geisslinger, G. (2014). Mechanismbased Treatment for Chemotherapy-Induced Peripheral Neuropathic Pain. Nat. Rev. Neurol. 10 (12), 694-707. doi:10.1038/nrneurol.2014.211

Slivicki, R. A., Iyer, V., Mali, S. S., Garai, S., Thakur, G. A., Crystal, J. D., et al. (2020). Positive Allosteric Modulation of CB1 Cannabinoid Receptor Signaling Enhances Morphine Antinociception and Attenuates Morphine Tolerance without Enhancing Morphine- Induced Dependence or Reward. Front. Mol. Neurosci. 13 (54), 54. doi:10.3389/fnmol.2020.00054

Slivicki, R. A., Saberi, S. A., Iyer, V., Vemuri, V. K., Makriyannis, A., and Hohmann, A. G. (2018). Brain-Permeant and -Impermeant Inhibitors of Fatty Acid Amide Hydrolase Synergize with the Opioid Analgesic Morphine to Suppress Chemotherapy-Induced Neuropathic Nociception without Enhancing Effects of Morphine on Gastrointestinal Transit. J. Pharmacol. Exp. Ther. 367 (3), 551-563. doi:10.1124/jpet.118.252288

Smith, S. B., Crager, S. E., and Mogil, J. S. (2004). Paclitaxel-induced Neuropathic Hypersensitivity in Mice: Responses in 10 Inbred Mouse Strains. Life Sci. 74 (21), 2593-2604. doi:10.1016/j.lfs.2004.01.002

Tidgewell, K., Harding, W. W., Schmidt, M., Holden, K. G., Murry, D. J., and Prisinzano, T. E. (2004). A Facile Method for the Preparation of Deuterium Labeled Salvinorin A: Synthesis of [2,2,2-2H3]-Salvinorin A. Bioorg. Med. Chem. Lett. 14 (20), 5099-5102. doi:10.1016/j.bmcl.2004.07.081

Tiwari, V., Anderson, M., Yang, F., Tiwari, V., Zheng, Q., He, S. Q., et al. (2018). Peripherally Acting $\mu$-Opioid Receptor Agonists Attenuate Ongoing PainAssociated Behavior and Spontaneous Neuronal Activity after Nerve Injury in Rats. Anesthesiology 128 (6), 1220-1236. doi:10.1097/ALN. 0000000000002191

Uniyal, A., Gadepalli, A., Kotiyal, A., and Tiwari, V. (2020). Underpinning the Neurobiological Intricacies Associated with Opioid Tolerance. ACS Chem. Neurosci. 11 (6), 830-839. doi:10.1021/acschemneuro.0c00019

van den Bent, M. J., van Raaij-van den Aarssen, V. J., Verweij, J., Doorn, P. A., and Sillevis Smitt, P. A. (1997). Progression of Paclitaxel-Induced Neuropathy Following Discontinuation of Treatment. Muscle Nerve 20 (6), 750-752. doi:10.1002/(sici)1097-4598(199706)20:6<750:aid-mus15>3.0.co;2-y

Vonvoigtlander, P. F., Lahti, R. A., and Ludens, J. H. (1983). U-50,488: a Selective and Structurally Novel Non-mu (Kappa) Opioid Agonist. J. Pharmacol. Exp. Ther. 224 (1), 7-12.

Wang, Y. C., Li, N., Zhao, Y., and Zhang, L. J. (2018). Effects of Female Sex Hormones on Chemotherapeutic Paclitaxel-Induced Neuropathic Pain and Involvement of Inflammatory Signal. J. Biol. Regul. Homeost Agents 32 (5), 1157-1163. 
Xu, M., Petraschka, J. P., McLaughlin, M. G., Czyzyk, T. A., Termanr, G. W., Chavkin, C., et al. (2004). Neuropathic Pain Activates the Endogenous Kappa Opioid System in Mouse Spinal Cord and Induces Opioid Receptor Tolerance. J. Neurosci. 24 (19), 4576-4584. doi:10.1523/JNEUROSCI.5552-03.2004

Conflict of Interest: The authors declare that the research was conducted in the absence of any commercial or financial relationships that could be construed as a potential conflict of interest.

Publisher's Note: All claims expressed in this article are solely those of the authors and do not necessarily represent those of their affiliated organizations, or those of the publisher, the editors and the reviewers. Any product that may be evaluated in this article, or claim that may be made by its manufacturer, is not guaranteed or endorsed by the publisher.

Copyright (c) 2022 Paton, Luo, La Flamme, Prisinzano and Kivell. This is an openaccess article distributed under the terms of the Creative Commons Attribution License (CC BY). The use, distribution or reproduction in other forums is permitted, provided the original author(s) and the copyright owner(s) are credited and that the original publication in this journal is cited, in accordance with accepted academic practice. No use, distribution or reproduction is permitted which does not comply with these terms. 